\title{
AVALIAÇÃO DO EFEITO ANTITUMORAL DA Kalanchoe brasiliensis SOBRE O SARCOMA 180 EM CAMUNDONGOS
}

\author{
Evaluation of antitumoral effevt of the kalanchoe brasiliensis on the \\ sarcoma 180 em camundongos
}

\author{
Marcos Cezar Feitosa de Paula Machado ${ }^{1,2}$; Mario Ribeiro de Melo-Junior ${ }^{1,3}$ \\ 1. Laboratório de Imunopatologia Keizo Asami (LIKA), UFPE, Brasil; \\ 2. Mestrado em Patologia, CCS, UFPE, Brasil; \\ 3. Associação Caruaruense de Ensino Superior (ASCES), Brasil
}

* Autor para correspondência e-mail: mariormj@gmail.com

Recebido em 03/09/2007 - Aceito em 17/12/2008

RESUMO: Atualmente, tem-se verificado a ação anti-tumoral de diversas plantas nativas do Brasil. Desta forma, o presente estudo testou in vivo a possível atividade anti-tumoral do extrato bruto da Kalanchoe brasiliensis frente a camundongos transfectados com o sarcoma 180. Foram utilizados animais que receberam, por via intraperitonial, uma solução aquosa de Kalanchoe brasiliensis contendo $50 \mathrm{mg} / \mathrm{Kg}$ do extrato diluído em salina. A forma sólida do tumor foi desenvolvida durante 7 dias. Os resultados indicaram que o extrato da planta Kalanchoe brasiliensis, apresentou efeito inibitório do crescimento tumoral frente o sarcoma 180, onde a redução estatisticamente significante $(p<0,05)$ da massa tumoral atingiu o percentual de $52,8 \%$. Entretatanto, não se verificou diferenças no peso corporal médio nos camundongos do grupo exposto ao extrato da planta quando comparado ao grupo controle. A partir desses resultados preliminares, podemos concluir que o extrato bruto da Kalanchoe brasiliensis guarda substâncias biologicamente ativas com evidente atividade anti-tumoral contra as células do Sarcoma 180.

PALAVRAS-CHAVE: Kalanchoe brasiliensis, Sarcoma 180, antitumoral

ABSTRACT: Nowadays, the anti-tumoral effects of several native plants of Brazil have been analyzed. This way, the present study tested the possible anti-tumoral activity of the aqueous extract of Kalanchoe brasiliensis in the mice exposed to sarcoma 180. The experimental model used animals that received though intraperitonial source, an aqueous solution from Kalanchoe brasiliensis containing $50 \mathrm{mg} / \mathrm{Kg}$ of the extract diluted in saline. The solid form of tumor was developed for 7 days. The results indicated that the extract of Kalanchoe brasiliensis presented important effect on the tumoral growth of the sarcoma 180, where the reduction statisticaly significant $(p<0.05)$ were the tumoral mass it plays reduction at $52.8 \%$. However, was not verified differences in the mean weight body in the animals from tumour exposed group when compared to the control group. Based on the preliminary results, we can conclude that the aqueous extract of the Kalanchoe brasiliensis present biologically active substances with evident anti-tumoral activity against the cells of the Sarcoma 180.

KEYWORDS: Kalanchoe brasiliensis, Sarcoma 180, antitumoral

\section{a) INTRODUÇÃO}

Atualmente, estão em expansão as linhas de pesquisas para novos compostos anti-neoplásicos e sua avaliação em vários sistemas tumorais e cultura de tecidos, objetivando selecionar compostos mais efetivos para o tratamento e controle das neoplasias (HUSSAR, 2000; ASLANI et al., 2000).

A cancerologia experimental é de grande valia para se estudar os diversos aspectos relacionados aos processos neoplásicos em humanos. O modelo animal para o estudo de tumores ganhou um novo impulso, na 
última década, após constatar-se que animais desenvolvem o câncer por motivos semelhantes aos humanos (QI \& XU, 2006).

As doenças tumorais neoplásicas vêm sendo indicadas como a terceira causa mortis mais freqüente no Brasil. Assim, as doenças cardiovasculares, o câncer e as causas externas são, conjuntamente, responsáveis por 73\% dos óbitos (INCA, 2008).

Para aperfeiçoar a reabilitação de lesões tumorais, podem-se utilizar biomateriais, compreendidos como materiais interativos capazes de estabelecer uma afinidade apropriada com tecido vizinho sem indução de uma resposta adversa do hospedeiro (SCHIRATO et al., 2006).

Estudos recentes demonstram que uma variedade de substâncias químicas isoladas de plantas que apresentam alguma atividade terapêutica. E muitas dessas substâncias tiveram como base para seu descobrimento estudos etnobotânicos e etnofarmacológicos (RODRIGUES, 2001; TREVISAN et al., 2006).

Inicialmente, os extratos brutos de plantas nativas brasileiras testadas, in vivo e in vitro, têm contribuído favoravelmente no processo anti-neoplásico podendo ser utilizado como biomateriais de ação farmacológica eficiente (SENEL \& MCCLUER, 2004).

A Kalanchoe brasiliensis proveniente da flora nordestina, é um exemplo de planta que vem sendo utilizada em diversas pesquisas e tem apresentado resultados terapêuticos satisfatórios, principalmente com ação antiulcerogênica (SILVA, 2003; LISBOA et al., 2006). Estudo recente discute também que o extrato de suas folhas revelou ações anti-fúngica, bactericida, analgésica e anti-inflamatória (TREVISAN et al., 2006).

A partir desses dados, o presente estudo testou in vivo a possível atividade anti-tumoral do extrato bruto da Kalanchoe brasiliensis frente a camundongos transfectados com o sarcoma 180.

\section{MATERIAL E MÉTODOS}

\section{Grupos experimentais}

Foram utilizados camundongos albinos suíços, Mus muscullus, do sexo feminino, pesando em média 24,6g. Os animais eram mantidos com dieta comercial LABINA ${ }^{\circledR}$ e água filtrada e inoculados com suspenção de células neoplásicas de sarcoma-180 na região axilar direita e após dois dias de implantados foram divididos de forma a compor dois grupos experimentais:

Grupo Experimental $(n=6)$ : Animais que receberam, também por via intraperitonial, uma solução aquosa de Kalanchoe brasiliensis contendo $50 \mathrm{mg} / \mathrm{Kg}$ do extrato diluído em salina (volume final = 3,5 $\mathrm{ml} / \mathrm{Kg} \mathrm{de} \mathrm{peso).} \mathrm{A}$ solução-teste foi extraída a partir da folha da Kalanchoe brasiliensis, utilizando-se a metodologia descrita por Schirato e colaboradores (2006);

Grupo Controle $(n=6)$ : Os animais recebiam por via intraperitonial doses de solução salina respeitando uma relação de acordo com seu peso ( $\mathrm{mg} / \mathrm{kg}$ de peso corpóreo), assim, eram submetidos ao mesmo estresse, causado pela contenção e injeção, sofrido pelos animais do grupo experimental.

\section{Manutenção do tumor experimental}

As células tumorais do Sarcoma 180 foram provenientes do Departamento de Antibióticos da Universidade Federal de Pernambuco (UFPE) e mantidas em camundongos através de passagens intraperitoneais semanais. 0 líquido ascítico com células tumorais do sarcoma 180 germinadas por 7 dias, foi aspirado e centrifugado (70g, 5 $\min , 4^{\circ} \mathrm{C}$ ). Através do sedimento realizou-se a contagem celular e teste de viabilidade celular com Azul de Tripan. A concentração de células viáveis foi ajustada com solução de $\mathrm{NaCl} 150 \mathrm{mM}$ estéril para $5,0 \times 10^{7} \mathrm{cé}^{2} \mathrm{lulas} / \mathrm{ml}^{-1}$. $\mathrm{O}^{\circ}$ volume de $0,1 \mathrm{ml}$ foi inoculado via subcutânea na região dorsal direita de cada camundongo, para que ocorresse o crescimento na forma sólida do tumor.

A forma sólida do tumor foi desenvolvida em camundongos durante 7 dias, até a formação de massa tumoral palpável que comprometia a mobilidade dos membros inferiores do animal. Após este período, todos os tumores foram retirados e pesados, com cada animal sendo previamente eutanasiado pelo método de deslocamento cervical e com os mesmos previamente anestesiados com a associação de cloridrato de xilazina e cloridrato de cetamina nas dosagens de $10 \mathrm{mg} / \mathrm{kg}$ e $115 \mathrm{mg} / \mathrm{kg}$, respectivamente, por via subcutânea.

O protocolo experimental deste trabalho foi aprovado pelo Comitê de Ética em pesquisa da UFPE.

\section{Análise dos dados}

Os dados referentes ao peso médio corporal e dos tumores foram submetidos à análise estatística, através do software PRISMA 3.0, pelo teste $t$ pareado. Os resultados obtidos foram expressos como média, aceitando-se como estatisticamente importantes os valores comparados ao nível de significância de $5 \%$. 
O sarcoma de camundongos (Sarcoma 180) foi um dos primeiros tumores experimentais a serem transplantados em animais. Inicialmente este tumor, descoberto em 1914 como uma massa sólida na axila direita de um camundongo branco, foi denominado de Tumor de Crocker. Esse tumor foi primariamente classificado como carcinoma mamário, mas após várias transplantações subcutâneas, observou-se que suas características morfológicas e seu comportamento eram característicos de um sarcoma e passou, então, a ser chamado de Sarcoma 180 (QI \& XU, 2006).

No presente estudo os tumores atingiram um volume médio de aproximadamente $2,52 \mathrm{~cm}$ em $7 \mathrm{dias}$ (Figura 1A e 1B). Todos os tumores eram sólidos, com poucas áreas necróticas ou hemorrágicas. No exame necroscópico não foram encontradas metástases.
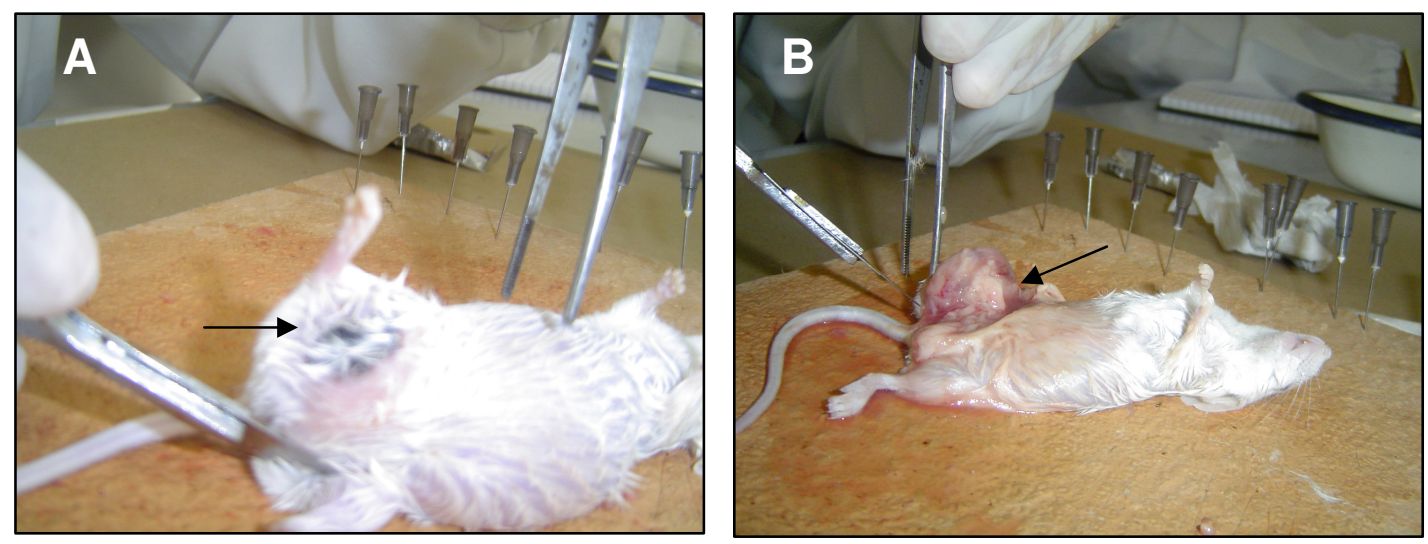

Figua 1. (A) Aspecto geral do tumor sarcoma 180 na pata direita de camundongo (seta). Em B observa-se à ressecção cirúrgica do tumor (seta) para avaliação ponderal.

Devido ao grande número de aplicações farmacológicas de substâncias naturais oriundas de plantas, recentes trabalhos têm investigado as atividades anti-tumorais desses produtos naturais (KIDD, 2000; ALVES et al., 2004). Esses fatores somados ao limitado efeito dos medicamentos sintéticos em doenças crônicas têm estimulado à pesquisa de plantas medicinais como alternativa terapêutica, com resultados bastante satisfatórios (RATNER \& BRYANT, 2004).

Em cancerologia experimental, os testes morfológicos e histoquímicos têm se tornado de grande importância para a triagem preliminar das mudanças moleculares induzidas por drogas antineoplásicas (QI \& XU, 2006).

Quanto à escolha do modelo biológico de neoplasias, ressalta-se a importância epidemiológica desta doença, responsável por grande parte dos óbitos no mundo e no Brasil. Entretanto, apesar dos sucessos em muitos casos, ainda não foi encontrado um tratamento que fosse simultaneamente eficaz e de baixa toxicidade (ROQUE \& FORONES, 2006).

Neste estudo, inicialmente foi avaliado o peso corporal e se verificou que tanto os camundongos do grupo exposto ao extrato da planta Kalanchoe brasiliensis bem como, o grupo controle não apresentou perdas significativas durante o período experimental (Gráfico 1).

Gráfico 1. Peso corporal médio dos camundongos transfectados com sarcoma 180 antes e após o tratamento com extrato bruto da Kalanchoe brasiliensis.

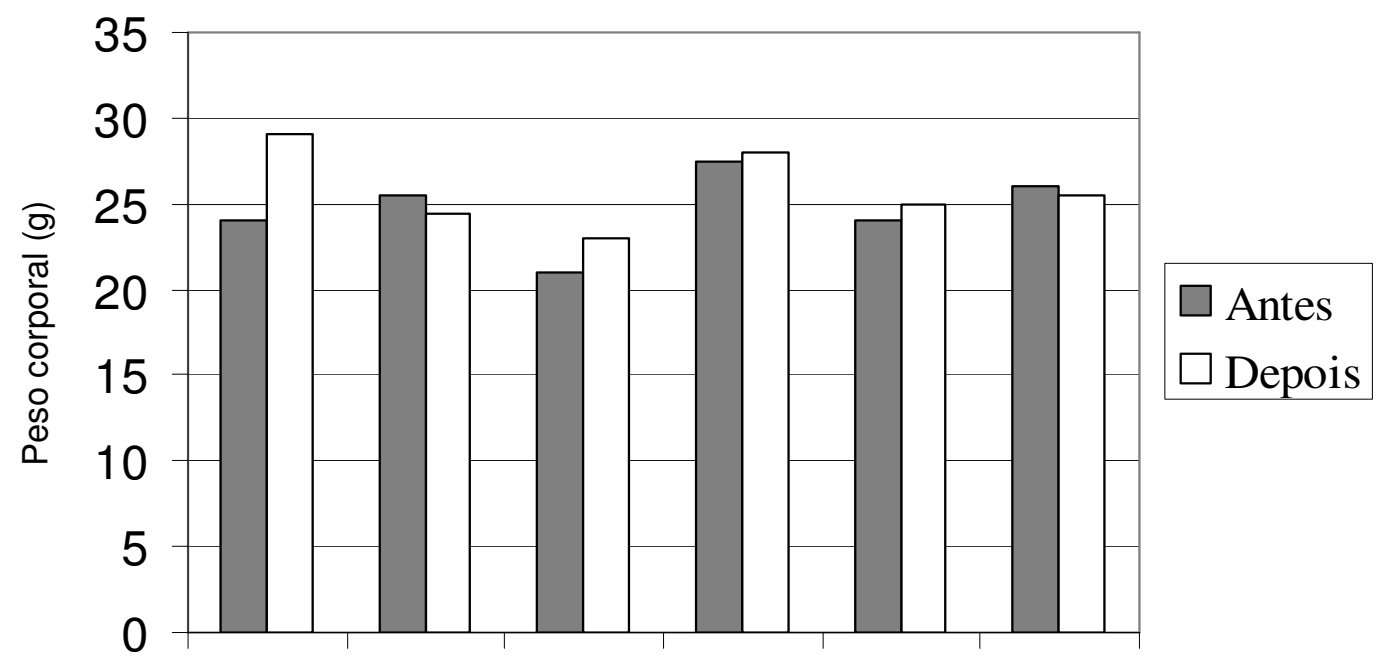


Parâmetros ponderais, como por exemplo, o peso dos tumores e variações da massa corpórea é de extrema valia para monitorar os efeitos de tratamento de drogas anti-neoplásicas (BEZERRA et al., 2006).

O extrato da planta Kalanchoe brasiliensis, apresentou efeito inibitório do crescimento tumoral frente o sarcoma 180, onde a redução estatisticamente significante $(p<0,05)$ da massa tumoral atingiu o percentual de $52,8 \%$. Esse percentual final de inibição foi calculado pela média dos tumores mensurados, 72 horas após a aplicação da droga como mostra o Gráfico 2.

Gráfico 2. Peso médio dos tumores em camundongos transfectados com Sarcoma 180 tratados com extrato bruto de Kalanchoe brasiliensis.

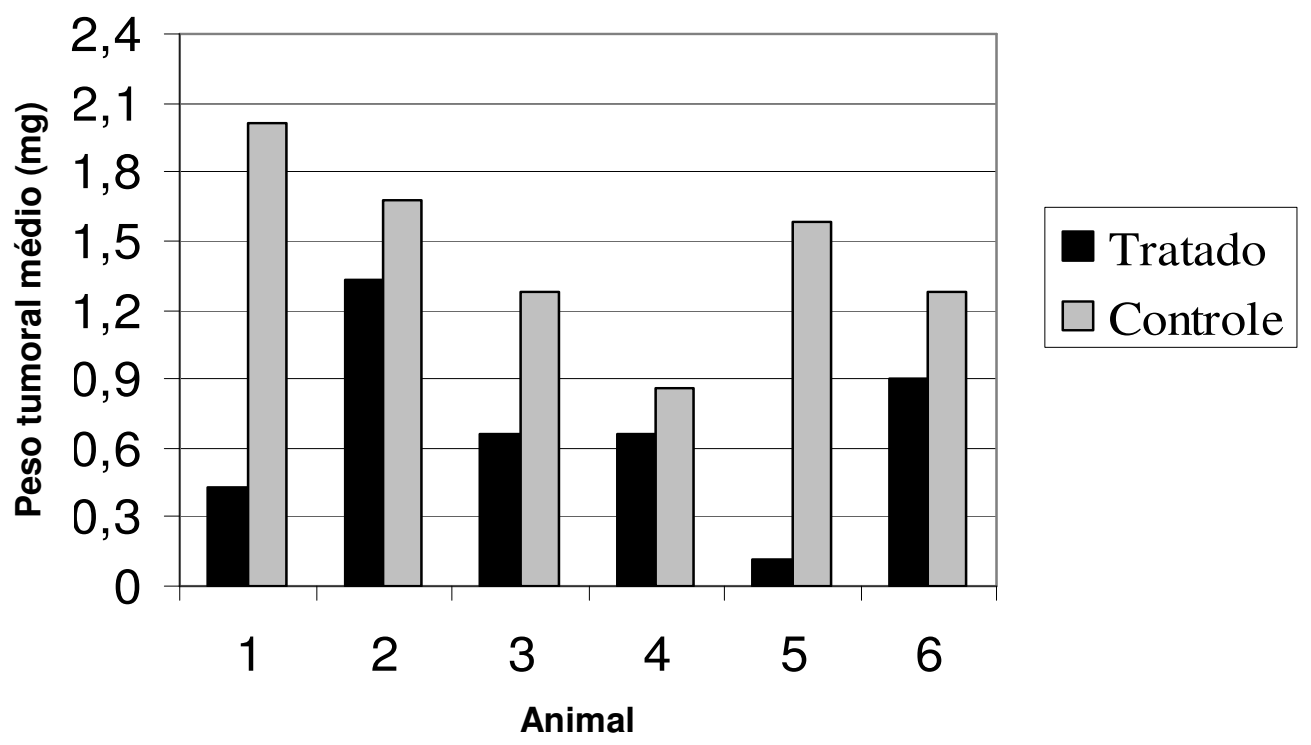

Trabalhos recentes demonstram que o extrato aquoso de plantas tem comprovado efeito citotóxico e antitumoral in vitro sobre células de melanoma (MUKHERJEE et al., 2001; LIMA et al., 2006). E mais especificamente, a partir de polissacarídeos isolados de plantas, se observou uma rejeição aos tumores experimentais implantados em ratos, que indicam também uma possível atividade imunomoduladora destas substâncias (FLORÊNCIO et al., 2007).

A Kalanchoe brasiliensis pertence à família Crassulaceae e tem origem incerta e tem distribuição desde a Bahia até São Paulo, de preferância na zona litorânea. Dentre os constituintes químicos principais encontra-se mucilagem, tanino, ácidos orgânicos, sais minerais e glicosídeos (LOREZI \& MATOS, 2002).

Estudo realizado por Ibrahim e colaboradores (2002) demonstrou de forma inédita, ações anti-inflamatória e imunosupressora da Kalanchoe em modelo experimental de doença reumática. Nesta linha de investigação estudo recente testou produtos oriundos desta planta e constataram um importante efeito inibitório sobre a linfocitopoiese (PAIVA et al., 2008).

Quanto ao comportamento dos animais, a partir do quarto dia após a administração do extrato da planta, foram observados os seguintes sintomas: piloereção, movimentos estereotipados, distenção abdominal, irritação ocular, espasmos, tremor fino. Outros estudos (ALVES et al., 2004) também apontam este tipo de comportamento associado à administração de certas drogas em cobais, entretanto, constata-se que estas alterações não interferem de forma significativa na resposta dos indivíduos aos diferentes tratamentos utilizados.

\section{CONCLUSÕES}

Neste contexto, visto que o extrato bruto da Kalanchoe brasiliensis guarda substâncias biologicamente ativas com evidente atividade anti-tumoral contra as células do Sarcoma $180 \mathrm{e} \mathrm{a} \mathrm{fim} \mathrm{de} \mathrm{confirmar} \mathrm{os} \mathrm{promissores}$ resultados obtidos neste estudo, se faz necessários estudos mais detalhados, como análises in vitro, a fim de se 
confirmar à atividade citotóxica da planta, bem como esclarecer os seus possíveis mecanismos imunomoduladores frente a um organismo portador de doença neoplásica maligna.

\section{AGRADECIMENTOS}

Os autores agradecem a colaboração da equipe de pesquisadores do Setor de Patologia do Laboratório de Imunopatologia Keizo Asami (LIKA), órgão suplementar da Universidade Federal de Pernambuco, pelo apoio técnico e financeiro.

b)

c) REFERÊNCIAS BIBLIOGRÁFICAS

ALVES, A.P.N.N.; GUEDES, R.C.; COSTA-LOTUFO, L.V. Modelo experimental de tumor na cavidade oral de ratos com carcinossarcoma de Walker. Acta Cir. Bras. v. 19, n. 4, p. 251-258, 2004.

ASLANI, A.; et al. The predictive value of body protein for chemoterapy-induced toxicity. Cancer. v. 88, p. 796-803, 2000.

BEZERRA D.P., CASTRO F.O., ALVES A.P.N.N., PESSOA C., MORAES M.O., SILVEIRA E.R. et al. In vivo growth-inhibition of Sarcoma 180 by piplartine and piperine, two alkaloid amides from Piper. Braz. J. Med. Biol. Res. v. 39, n. 6, p. 801-807, 2006.

FLORÊNCIO, A.P.S.; MELO, J.H.L.; MOTA, C.R.F.C.; MELO-JÚNIOR, M.R.; ARAÚJO, R.V.S. Estudo da atividade anti-tumoral do polissacarídeo (PJU) extraído de Anacardium occidentale frente a um modelo experimental do sarcoma 180. Rev. Eletron. Farm. v. 4, n. 1, p. 61-65, 2007.

HUSSAR, D. A. New drugs 2000. Part I. Nursing. v. 30, p. 55-62, 2000.

IBRAHIM, T.; CUNHA, J.M.T.; MADI, K.; FONSECA, L.M.B.; COSTA, S.S.; KOATZ, V.L.G. Immunomodulatory and anti-inflammatory effects of Kalanchoe brasiliensis. Int. Immunopharmacol. v. 2, n. 7, p. 875-883, 2002.

INCA. Instituto Nacional do Câncer. Ministério da Saúde, 2008. Estimativas da Incidência e Mortalidade por Câncer no Brasil [on line]. http://www.inca.org.br/epidemiologia/estimativa2008/neoplasia.html [acessado em 17 Dezembro de 2008].

KIDD, P. M. The use of mushroom glucans and proteoglycans in cancer treatment. Alternat. Med. Rev. v. 5, p. 427, 2000.

LIMA, A.P.; PEREIRA, F.C.; VILANOVA-COSTA, C.A.S.T.; RIBEIRO, A.S.B.B.; SILVEIRA-LACERDA, E.P. Avaliação da atividade antitumoral e citotóxica da planta Siolmatra brasiliensis. Rev. Eletron. Farm. v. 3, n. 2, p. 10-12, 2006.

LISBOA, M.S.; FEREIRA, S.M.; SILVA, M.S. Uso de plantas medicinais para tratar úlceras e gastrites pela comunidade do povoado Vila Capim, Município de Arapiraca-AL, Nordeste do Brasil. Sitientibus Cienc. Biol. v. 6, p.13-20, 2006.

LORENZI, H. \& MATOS, F.J.A. Plantas Medicinais no Brasil nativas e exóticas. 1ª Edição, São Paulo: Instituto Plantarum. 2002.

MUKHERJEE, A K.; BASU, S.; SARKAR, N.; GHOSH, A.C. Advances in cancer therapy with plant based natural products. Curr. Med. Chem. v. 8, n. 12, p. 1467-1486, 2001.

QI, L.\& XU, Z. In vivo antitumor activity of chitosan nanoparticles. Bioorganic Med. Chem. Letters. v. 16, n. 16, p. 4243-4245, 2006.

PAIVA, L.S.; HAYASHI, E.A.; MELO, G.O.; COSTA, S.S.; KOATZ, V.L.G.; NÓBREGA, A. Inhibition of B cell development by kalanchosine dimalate. Int. Immunopharmacol. v. 8, n. 6, p. 828-835, 2008.

RATNER, B.D.; BRYANT, S.J. Biomaterials: where we have been and where we are going. Ann. Rev. Biomed. Eng. v. 6, p. 41-75, 2004. 
RODRIGUES, A.G. Buscando Raízes. Horiz. Antropol. v. 16, p. 131-144, 2001.

ROQUE, V. M. N.; FORONES, N. M. Evaluation of the toxicity and quality of life in patients with colorectal cancer treated with chemotherapy. Arq. Gastroenterol. v. 43, n. 2, p. 32-38, 2006.

SCHIRATO, G.V.; MONTEIRO, F.M.F.; SILVA, F.O.; et al. The polysaccharide from Anacardium occidentale L. in the inflammatory phase of the cutaneous wound healing. Cienc. Rural. v. 36, n. 1 p. 149-154, 2006.

SENEL, S.; McCLURE, S.J. Potential applications of chitosan in veterinary medicine. Adv. Drug Delivery Rev. v. 56, p. 1467-1480, 2004.

SILVA, M.S. Avaliação farmacológica de plantas medicinais de uso popular contra distúrbios do trato gastrointestinal no povoado de Colônia Treze em Lagarto/SE (Dissertação de Mestrado) Universidade Federal de Sergipe. 94p. 2003.

TREVISAN, M.T.S.; BEZERRA, M.Z.B.; SANTIAGO, G.M.P.; FEITOSA, C.M. Atividades larvicida e colinesterásica de plantas do gênero Kolanchoe. Quim. Nova. v. 29, n. 3, p. 415-418, 2006. 